\title{
Medicaid and Welfare Reform
}

\section{Welfare Reform and Health Insurance of Immigrants}

\author{
Neeraj Kaushal and Robert Kaestner
}

Objective. To investigate the effect of the Personal Responsibility and Work Opportunity Reconciliation Act (PRWORA) on the health insurance coverage of foreign- and U.S.-born families headed by low-educated women.

Data Source. Secondary data from the March series of the Current Population Surveys for 1994-2001.

Study Design. Multivariate regression methods and a pre- and post-test with comparison group research design (difference-in-differences) are used to estimate the effect of welfare reform on the health insurance coverage of low-educated, foreign- and U.S.born unmarried women and their children. Heterogenous responses by states to create substitute Temporary Aid to Needy Families or Medicaid programs for newly arrived immigrants are used to investigate whether the estimated effect of PRWORA on newly arrived immigrants is related to the actual provisions of the law, or the result of fears engendered by the law.

Principal Findings. PRWORA increased the proportion of uninsured among low-educated, foreign-born, unmarried women by 9.9-10.7 percentage points. In contrast, the effect of PRWORA on the health insurance coverage of similar U.S.-born women is negligible. PRWORA also increased the proportion of uninsured among foreign-born children living with low-educated, single mothers by 13.5 percentage points. Again, the policy had little effect on the health insurance coverage of the children of U.S.-born, low-educated single mothers. There is some evidence that the fear and uncertainty engendered by the law had an effect on immigrant health insurance coverage.

Conclusions. This research demonstrates that PRWORA adversely affected the health insurance of low-educated, unmarried, immigrant women and their children. In the case of unmarried women, it may be partly because the jobs that they obtained in response to PRWORA were less likely to provide health insurance. The research also suggests that PRWORA may have engendered fear among immigrants and dampened their enrollment in safety net programs.

Key Words. Access to healthcare, social policy, immigrants

The Personal Responsibility and Work Opportunity Reconciliation Act (PRWORA) changed legal immigrants' access to public health insurance in two ways: directly, by denying Medicaid benefits to immigrants who arrived in the U.S. after August 1996, and indirectly, by denying or limiting immigrant participation in Temporary Aid to Needy Families (TANF), which is an 
important entry point into Medicaid. An explicit objective of Federal law was to restrict immigrant use of means-tested programs. However, many state governments responded to the immigrant provisions in PRWORA by creating substitute means-tested programs for those immigrants who were adversely affected by the Federal policy.

Despite this inclusive approach adopted by several states, immigrants' dependence on means-tested programs such as TANF, Medicaid, and Food Stamps fell sharply subsequent to the passage of the Federal law, raising concerns that the fear or stigma associated with PRWORA may have had a "chilling" effect, causing even those immigrants who were eligible for benefits not to seek them (Fix and Passel 1999). The decline was particularly noticeable for Medicaid, but its cause is unclear. The decline in Medicaid may have been a consequence of the provisions in PRWORA, or of the stigma attached to it; or the decline may have been the result of other factors such as the economic boom of the nineties. To date, research has not clearly established the relative importance of these or other causes.

If PROWRA was responsible for a decrease in immigrant health insurance coverage, it would most likely reduce health care utilization by poor immigrant families, and possibly adversely affect their health. However, if welfare reform induced immigrants to seek jobs that offered health insurance (reverse of crowd-out effect), the decline in Medicaid use may not have any adverse effect on immigrant health (Borjas 2003).

In this paper, we investigate whether PRWORA had an effect on the health insurance of low-educated, unmarried foreign-born women and their children, and compare that with the effect of welfare reform on the health insurance of native-born families with similar characteristics. We also study if newly arrived immigrants were affected by PRWORA more than their older cohorts. Finally, we examine the validity of the "chilling" hypothesis, which posits that immigrants responded not to the actual provisions of the law, but to the stigma or fear associated with it. To do so, we estimate the effect of PRWORA on new immigrants living in states with substitute TANF and/or Medicaid programs and on those living in states that do not provide these benefits to new immigrants. If the two groups were similarly affected by the policy change, it would be evidence consistent with the "chilling" hypothesis.

Address correspondence to Neeraj Kaushal, School of Social Work, Columbia University, 1255 Amsterdam Avenue, New York, NY 10027. Robert Kaestner is with the Department of Economics, University of Illinois at Chicago, 601 South Morgan 2108UH M/C144, Chicago, IL 60607. 


\section{IMMIGRANTS, HEALTH INSURANCE, AND PRWORA}

PRWORA altered legal (i.e., legal permanent residents) immigrants' access to public health insurance by denying immigrants who arrived in the U.S. after August 1996 Medicaid coverage for all but emergency care in the first five years of their residency. However, 15 states, including some large immigrant states such as California and Illinois, created substitute Medicaid programs for newly arrived legal immigrants. In the remaining states, which also include a number of major immigrant states like Texas, Florida, and New Jersey, newly arrived legal immigrants do not have access to Medicaid. ${ }^{1}$ Legal immigrants who arrived prior to August 1996 continue to have access to Medicaid in all states except Wyoming and illegal (i.e., illegally residing in the United States) immigrants continue not to have access to Medicaid.

PRWORA also denied post-August 1996 legal immigrants TANF in the first five years of their residency in the U.S. TANF is an important entry point into Medicaid, and so its denial may restrict immigrant use of public health insurance. Again, 19 states used state level funds to create substitute TANF programs to meet the welfare needs of newly arrived legal immigrants during the 5-year bar. Illegal immigrants and foreign-born persons on temporary visas experienced no change in policy, as they remain ineligible for TANF.

Finally, like citizens, all legal immigrants were potentially affected by the policy changes of PRWORA, which instituted time-limited benefits, imposed work requirements and sanctioned benefits if a recipient failed to meet the work requirements. The basic goal of PRWORA was to reduce dependence on public assistance and encourage economic self-sufficiency through work. As a result many low-income women were diverted from or encouraged to leave public assistance and this may have adversely affected their health insurance status. Women who leave TANF are eligible for transitional Medicaid benefits, but these benefits end after one year. Moreover, administrative hurdles may reduce take-up rates for transitional benefits. As the jobs that lowincome women typically get after leaving welfare do not provide health insurance coverage, a transition from welfare to work may also mean transition from state-provided insurance to no insurance. And there are no transitional benefits for women who are deterred from entering welfare. As many of these women are employed, their earnings may push them over the very low Medicaid income-eligibility thresholds for adults.

PRWORA did not distinguish between the pre-1996 legal immigrants and U.S. citizens, and the post-1996 legal immigrants have access to meanstested programs in states that have created substitute programs for newly 
arrived immigrants. As the law singles out only a small proportion of legal immigrants, the large relative declines in welfare and Medicaid observed among this group is a puzzle. ${ }^{2}$ Many observers believe that PRWORA created an atmosphere of fear and confusion among immigrants (Fix and Passel 1999). Surveys by the National Health Law Program and the National Immigration Law Center indicate that fear of deportation from the U.S. discouraged immigrants from obtaining publicly subsidized health care even when they were entitled to it (Schlosberg and Wiley 1998). This apparent unintended effect of PRWORA has been referred to as the "chilling" effect.

\section{PREVIOUS RESEARCH}

Several studies document a decline in Medicaid enrollment among low-income women and children after the implementation of welfare reform (Families USA Foundation 1999; Ku and Garrett 2000; Kronebusch 2001). Kaestner and Kaushal (2003) find that the approximately 50 percent decline in welfare caseload since 1996 increased the proportion of uninsured low-educated mothers by only 2-9 percent. They also report that changes in the welfare caseload owing to welfare reform had less adverse effects on health insurance coverage than changes in the welfare caseload owing to other factors such as a strong economy.

The effect of PRWORA on the health insurance status of immigrants is less widely researched. Borjas (2003) investigated the effect of PRWORA on the health insurance of nonelderly immigrants and found that the policy did not reduce their health insurance coverage. Although he found that welfare reform was associated with a decrease in Medicaid coverage, this decline was offset by an increase in private insurance.

Three aspects of this study merit comment. First, only a small fraction of nonelderly immigrants are eligible for Medicaid and TANF, and therefore PRWORA is likely to affect the health insurance coverage of a small portion of the sample. By using a sample of all nonelderly immigrants, Borjas (2003) assumes that the determinants of health insurance are the same for all subpopulations within this group. There may be significant heterogeneity in the determinants of health insurance coverage within the immigrant sample that may confound the effect of PRWORA. For example, the determinants of employer-sponsored health insurance may be quite different for young, single mothers than for older, married men. Thus, some effects of PRWORA may have been obscured in the Borjas' (2003) study. Second, Borjas (2003) uses a 
definition of the policy environment that is broad, and not focused on policies relating to health insurance. For instance, he assumes that denial of food stamps and SSI benefits would have the same effect on the health insurance of immigrants as the denial of Medicaid or TANF. Finally, Borjas (2003) uses natives as a comparison group for immigrants and obtains estimates of the difference in the effect of PRWORA on immigrants relative to natives. This is not the same as measuring the effect of PRWORA on immigrant health insurance. Further, this approach assumes that, in the absence of PRWORA, changes in immigrant and native health insurance status pre- and post-PRWORA would have been the same, which is inconsistent with the mean levels of health insurance that differ significantly between noncitizens and natives.

Our research differs from that of Borjas (2003) in several ways. First, we focus on a group that is more likely to be affected by welfare reform-loweducated, unmarried women and their children - than the group examined by Borjas (2003). Second, we use other immigrants instead of natives as a comparison group. Third, we specifically look at changes in Medicaid and TANF policies, the two aspects of PRWORA that are most likely to affect health insurance of low-educated, unmarried women and their children. ${ }^{3}$

\section{RESEARCH DESIGN}

Our objective is to obtain estimates of the association between federal welfare reform (PRWORA) and health insurance coverage of low-educated, foreignand U.S.-born single women and their children. Ideally, we would like to obtain estimates that can plausibly be given a causal interpretation. Therefore, we use multivariate regression methods and a pre- and post-test with comparison group research design. The starting point of this empirical approach is the following regression model:

$$
\begin{aligned}
\text { Insurance }_{i j t} & =\alpha+\beta_{j}+\delta_{j t}+\lambda_{c}+\gamma \text { Policy }_{j t}+Z_{j t} \Delta+X_{i j t} \Gamma+u_{i g i t} \\
i & =1, \ldots, N \text { (persons); } \quad c=1, \ldots, C \text { (country of birth); } \\
j & =1, \ldots, 51 \text { (states); } \quad t=1993, \ldots, 2000 \text { (years) }
\end{aligned}
$$

In equation (1), health insurance status (e.g., Medicaid) of woman $i$ from country $c$ (if foreign born) in state $j$ and year $t$ is a function of welfare reform, which we measure as a dummy variable $\left(\right.$ Policy $\left._{j t}\right)$ that equals one if state $j$ had implemented TANF in year $t$, and zero otherwise; state characteristics $\left(Z_{j t}\right)$ such as Medicaid income eligibility threshold, unemployment rate, and lagged unemployment rate; individual characteristics $\left(X_{i j t}\right)$ such as age, race, 
education, other family income, family composition, citizenship status (if foreign born), number of years lived in the U.S. (if foreign born), and whether arrived in the U.S. prior to 1996 (if foreign born); state-fixed effects $\left(\beta_{j}\right)$; and country-fixed effects $\left(\lambda_{c}\right)$. In addition, we include state-specific quadratic time trends $\left(\delta_{j t}\right)$ to capture unmeasured, time-varying state effects. Over a relatively short period, as in the current context, quadratic time trends may be expected to approximate reasonably well, unmeasured, time-varying state-specific influences. A similar model is used in the analysis of children's health insurance coverage.

We estimate equation (1) for two groups: those likely to be affected by PRWORA and those unlikely to be affected by it. We refer to the former as the target group and the latter as the comparison group. As the comparison group is mostly unaffected by PRWORA, estimates of the effect of policy on this group quantify the effect of unmeasured variables that affect health insurance and are correlated with welfare reform. To obtain the "causal" effect of PRWORA on the health insurance of the target group, we subtract the effect of PRWORA on the comparison group from the effect on the target group. This approach is commonly referred to as difference-in-differences (DD). The DD estimates can also be obtained directly using the following specification:

$$
\begin{aligned}
& \text { Insurance }_{i c t}= \tilde{\alpha} \\
&+(\alpha-\tilde{\alpha}) \text { Treat }_{i}+\tilde{\beta}_{j}+\left(\beta_{j}-\tilde{\beta}_{j}\right) \text { Treat }_{i}+\tilde{\lambda}_{c} \\
&+\left(\lambda_{c}-\tilde{\lambda}_{c}\right) \text { Treat }_{i} \\
&+\tilde{\delta}_{j t}+\left(\delta_{j t}-\tilde{\delta}_{j t}\right) \text { Treat }_{i}+\tilde{\gamma} \text { Policy }_{j t} \\
&+(\gamma-\tilde{\gamma})\left(\text { Policy }_{j t} \times \text { Treat }_{i}\right) \\
&+Z_{j t} \tilde{\Delta}+\left(Z_{j t} \times \operatorname{Treat}_{i}\right)(\Delta-\tilde{\Delta})+X_{i g j t} \tilde{\Gamma} \\
&+\left(X_{i j t} \times \text { Treat }_{i}\right)(\Gamma-\tilde{\Gamma})+v_{i g j t} .
\end{aligned}
$$

The only new variable in equation (2) is "Treat," which is equal to one if the observation is from the target group, and zero if it is from the comparison group. The DD estimate of the effect of welfare policy is $\gamma-\tilde{\gamma}$. Equation (2) is the least restrictive specification as it allows for a complete set of interactions between the covariates and the target group dummy variable (Treat). The only identifying restriction is that, in the absence of PRWORA, unmeasured stateyear influences on the health insurance status of the target and comparison groups would have been the same. ${ }^{4}$

A second objective of the research is to test the "chilling" hypothesis. We employ three strategies to discern the presence of the "chilling" effect. We first divide the target group in two categories: those who arrived in the U.S. less 
than 5 years ago and those who arrived 5 or more years ago. If the two groups are similarly affected by PRWORA, that would provide evidence consistent with the "chilling" hypothesis, as newly arrived immigrants are subject to more severe policy changes and therefore should be more adversely affected than immigrants who came to the U.S. in earlier years. Next, we test the "chilling" hypothesis on the post-1996 immigrants. We exploit the heterogenous responses by states to create a substitute TANF or Medicaid program for newly arrived immigrants to investigate whether the estimated effect of PRWORA on newly arrived immigrants is related to the actual provisions of the law. We divide immigrants in two groups: post- and pre-1996 immigrants. These two groups are further sub-divided depending on immigrant's state of residence, that is, whether an immigrant lives in a state with at least a substitute Medicaid or TANF program for newly arrived immigrants or in a state with neither of the two programs. If the two groups of post-1996 immigrants are similarly affected by PRWORA that would again be evidence consistent with the "chilling" effect. By allowing the effect of the policy to differ for the pre1996 immigrant group, we are able to test whether the difference in effect for the post-1996 immigrants is a state effect or a policy effect.

Finally, we test the chilling hypothesis in the children's analysis by comparing the effect of PRWORA on foreign-born children of foreign-born parents and U.S.-born children of foreign-born parents. U.S.-born children of foreign-born parents are not affected by the immigrant provisions since they are U.S. citizens. Therefore, PRWORA should have a more muted effect on their health insurance status vis-à-vis foreign-born children of foreign-born parents. If not, this would again be evidence consistent with the "chilling" hypothesis. ${ }^{5}$

\section{Selecting Target and Comparison Groups}

The efficacy of the pre- and post-test with comparison group research design depends critically on the validity of the target and comparison groups. Identifying a target group is relatively straightforward, as we need to identify a group likely to be affected by PRWORA. A good choice is single mothers and their children as these families constitute the majority of the welfare caseload (Kaestner and Kaushal 2003). However, owing to sample size considerations, particularly with respect to immigrants, we cannot limit the analysis to women with children. Therefore, we use all low-educated unmarried women as our target group. However, to see if our analysis is broadly indicative of the impact on the more vulnerable group, that is, low-educated single mothers, we also repeat the analysis restricting the sample to low-educated single mothers. 
According to the March Current Population Survey, in 1993, 20 percent of unmarried, foreign-born women aged 18-44 years, with 12 or fewer years of education, received TANF and 31 percent were covered by Medicaid, which is a good indicator of potential risk of receipt of public assistance. ${ }^{6}$ Indeed, given that AFDC is the primary point of entry for Medicaid among adults, and 99 percent of those on welfare also received Medicaid, the significantly larger proportion of the sample that is covered by Medicaid is consistent with the notion that a larger proportion of the sample is at risk of entering the AFDC program. ${ }^{7}$ It is important to note that these figures on program participation represent the minimum proportion of women likely to be affected by PRWORA since a significantly larger proportion of women are at risk of receiving public assistance and therefore their behavior may be influenced by welfare policy. Nevertheless, the fact that not 100 percent of the target group is affected by changes in the policy will result in downward biased DD estimates of the effect of PRWORA on insurance status (i.e., the effect of treatment on the treated). For example, if only 50 percent of the target group is at risk, estimates obtained using this group will be half as large as the true effect of interest.

The choice of the comparison group is more difficult. Ideally, the comparison group should consist of those whose health insurance coverage and the determinants of that coverage are similar to the target group, but who are unlikely to be affected by welfare reform. One comparison group we use is low-educated, married women with the same nativity status. A drawback of using this comparison group is that a small fraction (approximately six percent) of this group is at risk of receiving public assistance. This results in additional downward bias. Continuing with the example above, if 50 percent of the target group are at risk and 10 percent of the comparison group are at risk, then the estimated effect will be 40 percent of the true causal effect. ${ }^{8}$ In the case of immigrants, the misclassification bias may be larger because we cannot distinguish between permanent legal residents, those affected by PRWORA, and other immigrants (e.g., undocumented immigrants). Therefore, estimates of the effect of PRWORA may differ between natives and immigrants.

The second comparison group we use is low-educated (education $\leq 12$ years) men, a group that is unlikely to be affected by welfare reform. The advantage of this group is that no members of this group are eligible for (federal) public assistance. However, given differences in male and female labor market opportunities, it is uncertain whether the determinants of health insurance coverage of this group are similar to that of unmarried, low-educated women. We comment further on this point below. 
The target groups in the children's analysis are children of U.S.-born, low-educated, single mothers and children of foreign-born, low-educated, single mothers. The latter is further stratified according to child's nativity status. Our comparison groups are children of low-educated, married mothers with the same nativity status as the target group. So, e.g., in the analysis of foreign-born children of foreign-born single mothers, the comparison group is foreign-born children of foreign-born married mothers.

It is difficult to assess the validity of the comparison groups. We chose to compare families with similar levels of education, given the importance of education in determining welfare participation and labor market opportunities. We also hold constant many important observed determinants of health insurance. To test the validity of our methodology, we implemented a DD procedure in years prior to PRWORA (1993-1995) in states that did not introduce an AFDC waiver during 1993-1995. We assumed that there was a policy intervention in 1994. If the assumptions underlying the DD analysis are valid, the estimated effect of the pseudo-policy should be zero. In fact, DD estimates were negligible, for example the pseudo-policy intervention in 1994 increased Medicaid use of unmarried, low-educated, foreign-born women by a statistically insignificant 0.3 percentage points; increased private insurance by a statistically insignificant 0.1 percentage points; and lowered proportion without insurance by a statistically insignificant one percentage point. ${ }^{9}$

Another way to assess the accuracy of our research design is to compare the mean rates of insurance coverage of the target and comparison groups. Means of roughly similar magnitudes would suggest that the insurance status of the two groups is influenced by similar factors. Moreover, similar means also eliminate the need to choose between an analysis based on relative changes vis-à-vis absolute changes.

Table 1 presents mean rates of insurance coverage for the target and comparison groups used in the analysis, and shows that prior to federal welfare reform, unmarried women had much higher rates of public health insurance coverage than either of the comparison groups, as would be expected given eligibility rules, which depend heavily on family structure. However, the rates of the uninsured are similar for the target group and two comparison groups, and the proportion of unmarried and married women covered by employersponsored insurance is similar. Low-educated men have a higher proportion of employer-sponsored insurance than either married or unmarried women.

Children's insurance status, also reported in Table 1, shows that public insurance coverage of children living with single mothers is much higher than public insurance of children living with married mothers, irrespective of their 


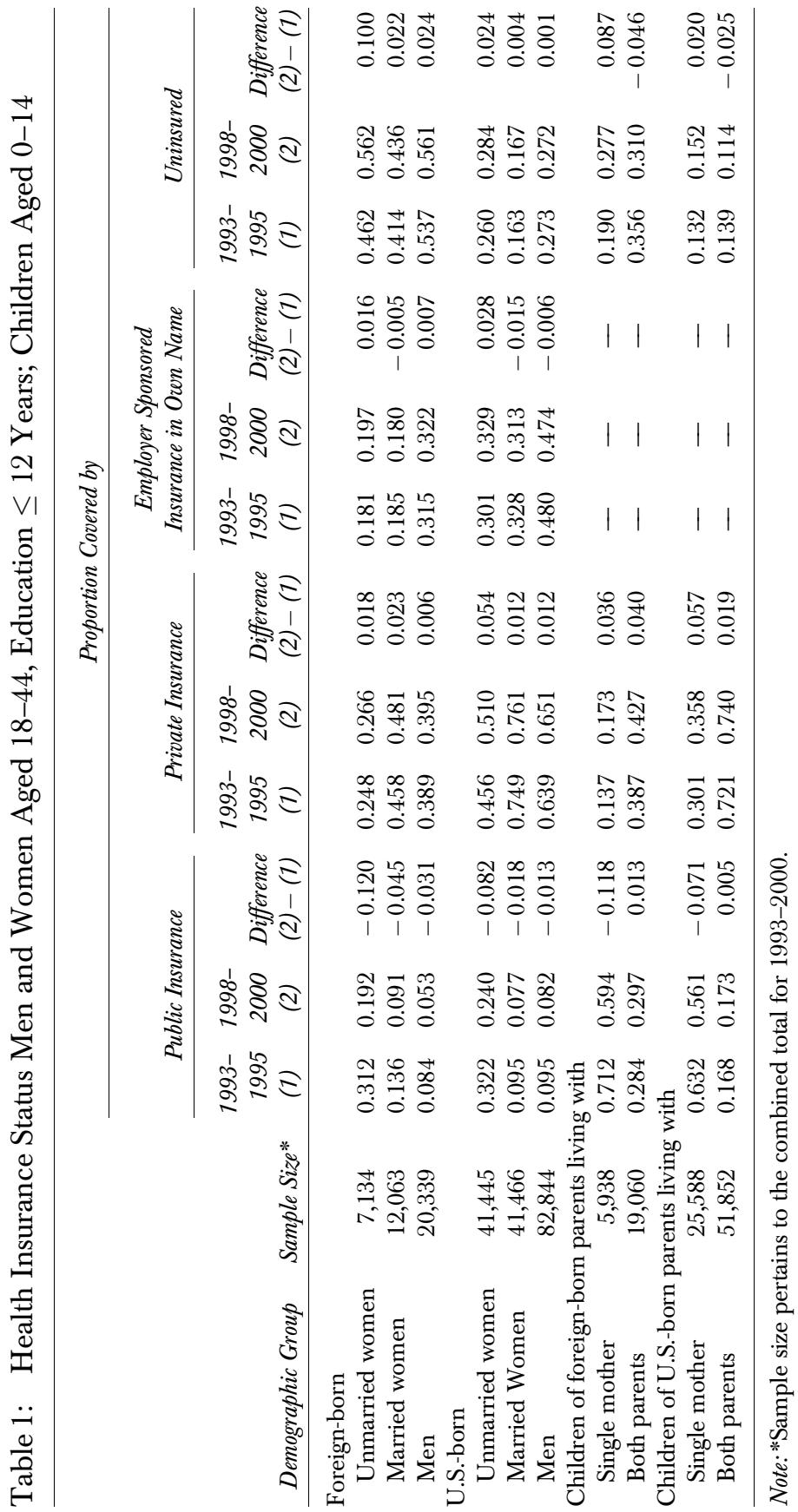


nativity status. Among children of foreign-born single mothers not covered by Medicaid, the net health insurance coverage is roughly the same for the target and comparison groups.

To summarize, it is clear that we do not have a very good comparison group for the public insurance outcome, particularly for adult women. Welfare reform is intended to deter participation in AFDC/TANF and as a result will cause a decrease in Medicaid coverage. Married women and unmarried men are largely ineligible for AFDC/TANF and Medicaid. Therefore, changes in these two groups' public health insurance coverage may not provide the appropriate counterfactual. This is less true for children. ${ }^{10}$ Accordingly, we place less emphasis on the difference-in-differences estimates for this outcome. ${ }^{11}$ But for the private health insurance coverage (all types and employer-sponsored) and uninsured outcomes, we have identified reasonable comparison groups, and tests of the underlying assumption of the DD procedure support our use of these groups.

We recognize the difficulty of identifying "ideal" target and comparison groups. At the very least, the comparison group approach we employ identifies whether any observed effects of welfare reform on health insurance status are group-specific, and whether the effects are primarily found for the group of interest - the target group. If the identifying assumption of the difference-indifferences procedure is valid, then our estimates may be given a causal interpretation. Finally, the estimates we obtain using the difference-in-differences procedure will be biased toward zero because not all members of the target group are at risk of being affected by welfare reform and because a small proportion of those in the comparison group are at risk.

\section{DATA}

The data for the analysis come from the March series of the Current Population Surveys for 1994-2001, which provide information on respondent's health insurance status for the years 1993-2000. A key aspect of this data for our analysis is that, since 1994, the CPS has been providing information on the respondent's citizenship status, country of birth, and year of arrival in the U.S. The sample in our analysis consists of low-educated women and men aged 18 to 44 . We stratify the sample according to respondent's nativity status. In the children's analysis, the sample is limited to children aged 0 to 14 whose mothers have 12 or fewer years of education and are 18 to 44 years of age. We study the children of U.S.-born and foreign-born parents. 
The target of immigrant provisions in PRWORA is the noncitizen. Foreign-born citizens are not treated differently from U.S.-born citizens. Ideally, foreign-born citizens should be excluded from the analysis as they are unaffected by the immigrant provisions in PRWORA. However, if PRWORA induced immigrants to become citizens so that they could continue to have access to means-tested programs, exclusion of citizens would result in a selectivity bias. There is evidence of increased naturalization throughout the 1990 s, which is mostly attributed to increased immigration in the early 1990 s and the 1986 Immigration Reform and Control Act, which granted permanent legal status to approximately 2.7 million immigrants (Fix and Haskins 2002). However, it is not possible to rule out that some immigrants naturalized in response to welfare reform and its differential treatment of noncitizens. To address this issue, we do the analysis by combining the samples of foreignborn citizens and noncitizens. ${ }^{12}$ This approach eliminates the selection bias relating to naturalization.

We define four categories of insurance: public insurance, which includes Medicaid, SCHIP, and other publicly provided insurance; private insurance, which includes employer-sponsored and individual private insurance plans; employer-sponsored insurance in the respondent's own name; and uninsured. ${ }^{13}$ Starting with the 2000 survey (1999 health insurance information), the CPS has an additional health insurance "verification question" that has caused a reduction in the estimates on the percent uninsured (Nelson and Mills 2001). To control for the change in CPS estimation measures, we include a post-1998 dummy in the multivariate analysis.

The CPS contains all the basic demographic information that is used to construct control variables and information that allows us to link children to their mothers. The CPS also provides respondents' state of residence, which allows us to append state-level information such as state and federal welfare policy, Medicaid income eligibility threshold and the unemployment ratecurrent and lagged by one-year. ${ }^{14}$ For women, state Medicaid eligibility variables are defined on the basis of Medicaid eligibility of pregnant women. For children, Medicaid eligibility is specific to a child's age and is the higher of the Medicaid or SCHIP income eligibility threshold. The data on welfare policies are drawn from Assistant Secretary for Planning and Evaluation of the Department of Health and Human Services, the Urban Institute (www.urban. $\mathrm{org} /$ content/Research/NewFederalism/Data/StateDatabase/StateDatabase. $\mathrm{htm}$ ), and from the information reported in Zimmerman and Tumlin (1999). We measure welfare reform using two indicators: a dummy variable equal to one if the state implemented an AFDC waiver and a dummy variable equal to 
one if the state implemented TANF. The AFDC waiver is set to zero when TANF is one. All state-level variables are merged to the CPS data in the year prior to the survey year. So the 1998 welfare policies are merged to the 1999 CPS.

\section{RESULTS}

\section{Descriptive Analysis}

Table 1 presents the health insurance status of various demographic groups, which define our target and comparison groups, in 3 years prior to the passage of PRWORA and 3 years after its passage, and provides some preliminary evidence of the effect of the policy change on the health insurance status of these groups. It shows that Medicaid coverage of unmarried, low-educated, foreign-born women, the group most vulnerable to the policy change among foreign-born adults, fell by 12 percentage points after the passage of PRWORA. In comparison, Medicaid coverage of unmarried, low-educated, U.S.-born women, the most vulnerable group among the U.S.-born adults, fell by 8.2 percentage points. While the private insurance of U.S.-born women rose by 5.4 percentage points during this period, the increase in the private coverage of foreign-born women was just 1.8 percentage points. These changes resulted in a 10 percentage point increase in the proportion of the uninsured among foreign-born women and a 2.4 percentage point increase in the proportion uninsured among U.S.-born women.

Table 1 also presents changes in health insurance of the comparison groups by nativity in the pre- and post-PRWORA period. These changes are relatively modest as compared with the corresponding changes for the target groups. These data provide some preliminary evidence to support the widely held view that welfare reform caused a decrease in insurance coverage among low-educated single women, and the effect appears more severe on foreignborn women as compared with U.S.-born women.

A similar story emerges for children of single mothers. Medicaid dependence among children of foreign-born women is greater than that among children of native-born women. Children of foreign-born single mothers also registered a greater decline in Medicaid coverage since the passage of PRWORA. Private insurance of children of foreign-born single mothers increased by a lower proportion as compared with the increase in the case of children of U.S.-born single mothers. As a result, the number of uninsured children living with unmarried, low-educated, foreign-born mothers increased 
by 8.7 percentage points after the passage of PRWORA, while the increase in the uninsured among children of U.S.-born mothers with the same education and marital status was two percentage points. In contrast, the proportion uninsured among the comparison groups-children of low-educated married mothers-actually declined with the decline being greater among the children of foreign-born, married women.

In short, the data in Table 1 suggest that PRWORA has adversely affected the health insurance of foreign-born, unmarried women and their children more than that of natives. This analysis is based on unadjusted data. Arguably, the effect of welfare policy could be because of other factors that may be correlated with the policy change. To address these issues, we now turn to the multivariate analysis outlined above.

\section{Multivariate Analysis - Women}

Table 2 presents estimates of the effect of TANF (the cash assistance component of PRWORA) on the health insurance coverage of low-educated, U.S.and foreign-born women. All estimates are obtained by ordinary least squares. Standard errors, reported in parenthesis, are calculated under the assumption that observations from the same state are not independent. Each column of Table 2 is from a different regression and each regression controls for family size, other family income, age, race, education, number of kids and number of young kids, state Medicaid eligibility, unemployment rate (current and with a lag), whether a state had an AFDC waiver prior to TANF implementation, state-fixed effects and state-specific quadratic trends. ${ }^{15}$ Each regression also includes a post-1998 dummy to control for the changes in health insurance measures after the introduction of the "verification" question in the CPS. The analysis on foreign-born women also controls for citizenship status, country-ofbirth fixed effects, whether arrived prior to 1996 and year of arrival in the U.S. ${ }^{16}$

Row 1 in Table 2 presents the result of the first-difference analysis (based on equation (1)) in which the samples are restricted to the target groups. It shows that TANF reduced the Medicaid coverage of foreign-born, single women by a statistically insignificant 3.4 percentage points, reduced their private insurance by a statistically insignificant 1.5 percentage points, and increased the proportion uninsured by a statistically insignificant 4.8 percentage points. The analysis on U.S.-born single women suggests that TANF had small and statistically insignificant effects on their health insurance outcomes.

It is interesting to compare the estimates of the associations between TANF and insurance status in row 1 of Table 2 to the figures in Table 1. For 


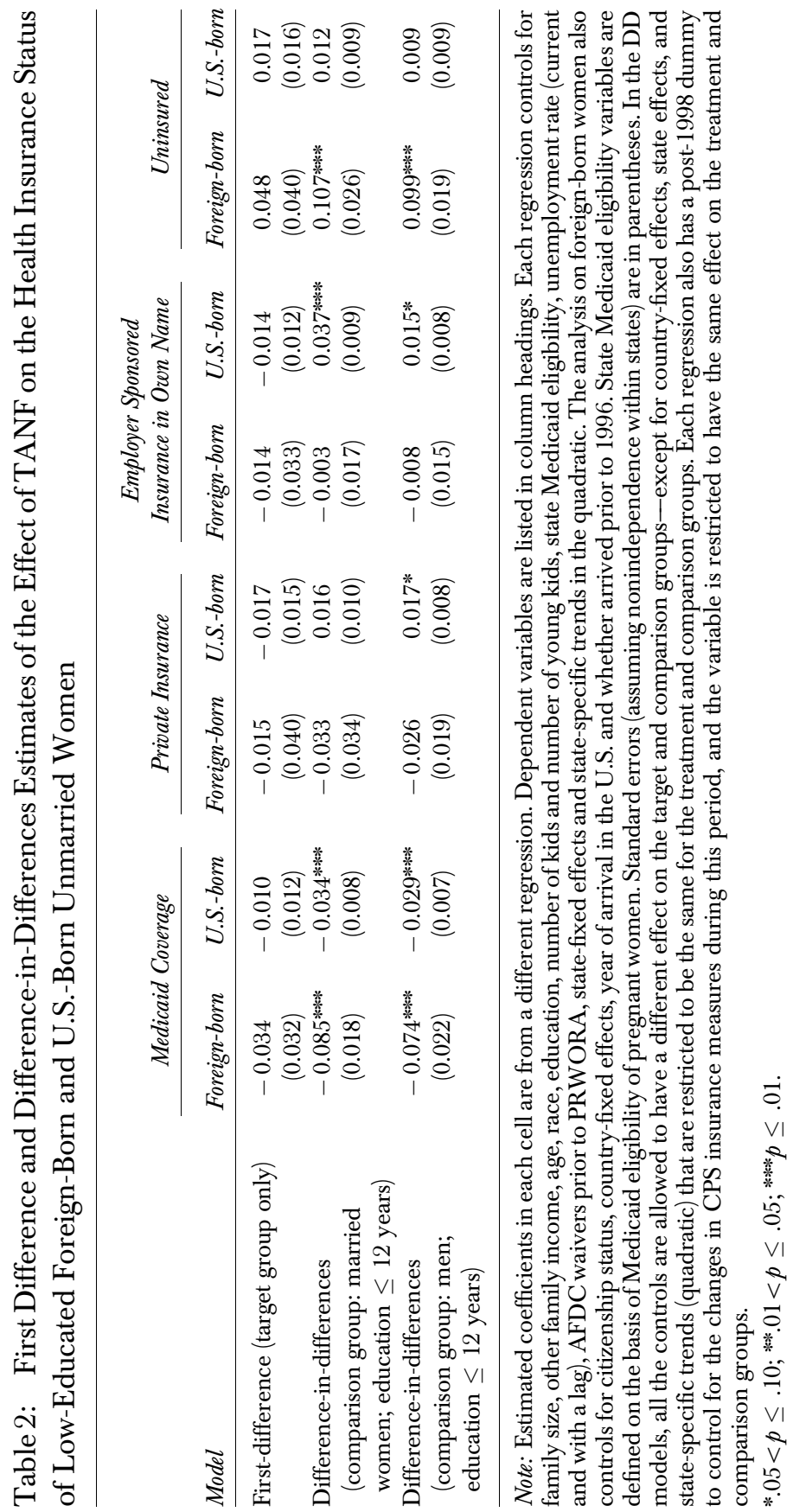


example, figures in Table 1 indicate that between 1993/95 and 1998/2000, the proportion of foreign-born, unmarried women with Medicaid decreased by 12 percentage points. Estimates in row 1 of Table 2 show that TANF is associated with a 3.4 percentage point decrease in Medicaid coverage for this group. Similar differences are observed for U.S.-born women. In general, the different inferences that are derived from estimates in Tables 1 and row 1 of Table 2 reveal that there were significant trends in insurance coverage during this period and that care needs to be taken to isolate the effect of policy from these trends. The difference-in-differences procedure is designed to account for these trends, and its results are presented in row 2 (comparison group: married, low-educated women of corresponding nativity) and row 3 (comparison group: low-educated men of corresponding nativity). We use the least restrictive difference-in-differences model in which all the controls are allowed to have a different effect on the target and comparison groups, except for those that statistical tests suggested could be constrained. Although we present the DD estimate for Medicaid (as for the other outcomes), we remind the reader that the comparison group approach may be least valid for this outcome.

Estimates in rows 2 and 3 show that for foreign-born women, TANF significantly reduced Medicaid coverage by between 7.4 and 8.5 percentage points; reduced private insurance coverage by a statistically insignificant 2.63.3 percentage points; lowered employer-sponsored insurance by a statistically insignificant $0.3-0.8$ percentage points; and raised the proportion uninsured by a statistically significant $9.9-10.7$ percentage points. The increase in the proportion of uninsured is approximately equal to the decrease in Medicaid. As can be seen, the choice of comparison group makes little difference to the estimates.

As we noted above, not all women in our target group are affected by welfare reform and this misclassification results in downward biased estimates. To investigate how sensitive estimates are to choice of target group, we reestimated the models in Table 2 using a group of low-educated, unmarried mothers. The results from this analysis (not shown in Table 2) indicate that PRWORA lowered Medicaid use of unmarried, low-educated, foreignborn mothers by a statistically significant 11.2 percentage points; raised their private insurance by a statistically insignificant 1.6 percentage points and raised the proportion uninsured by a statistically significant 8.5 percentage points. The larger effects among mothers are consistent with expectations, as the misclassification for this group is smaller and estimates less biased toward zero. 
Among U.S.-born women, TANF resulted in a statistically significant decrease in Medicaid coverage of between 2.9 and 3.4 percentage points, and a statistically significant increase in employer-sponsored health insurance coverage of between 1.5 and 3.7 percentage points. Consistent with these results, TANF had little effect on the rate of uninsured. Again, we carry out a similar analysis using mothers instead of all low-educated, unmarried women to see whether estimates in Table 2 are affected by such a change. Results (not presented in Table 2) indicate that that welfare reform lowered Medicaid use of unmarried, low-educated (native) mothers by a statistically significant 5.8 percentage points; increased their private insurance by a statistically significant 2.9 percentage points; and increased the proportion uninsured by 2.1 percentage points.

To sum up, estimates indicate that TANF is associated with an increase in the proportion of foreign-born women who are uninsured. This is a result of a decrease in Medicaid coverage that was not offset by an increase in employer-sponsored coverage, as was the case among U.S.-born women.

We are also interested in assessing whether the effect of welfare reform on immigrants differed by the length of their stay in the United States. New immigrants, singled out under PRWORA, have particularly low rates of health insurance coverage (Camarota and Edwards 2000). To see whether PRWORA affected newly arrived immigrants differently, we repeat the DD analysis on two groups: those who arrived in the last 5 years and those who arrived more than 5 years ago. We find that the effect of TANF on the health insurance coverage of foreign-born, unmarried women did not differ by their length of stay in the U.S. This finding is consistent with the "chilling" hypothesis since the estimated effect of TANF is the same even though groups were subject to different policies. On the other hand, if most new immigrants lived in states that created substitute TANF and Medicaid programs, we may expect this result. However, there is little empirical evidence to support that this is in fact the case (Kaushal 2005). Our finding may also be the result of differing degrees of bias in the DD estimates if a smaller proportion of newly arrived immigrants received welfare benefits as compared with old immigrants. Data on welfare receipt from the CPS suggest that this may be the case. Among low-educated, unmarried, foreign-born women (i.e., members of the target group), 11 percent of the newly arrived received AFDC income in the past year as compared with 22 percent of those who have been living in the U.S. for 5 years or more. Therefore, the (downward) bias of the DD estimates may differ and obscure true underlying differences in effects. 


\section{Chilling Hypothesis}

In this section, we investigate more thoroughly the "chilling" hypothesis by exploiting the variation in state policies that were intended to offset the changes in TANF and Medicaid embedded in PRWORA. We construct two variables to describe the policy environment for newly arrived immigrants: "Medicaid and/or TANF" is equal to one if a state has a substitute TANF and/ or Medicaid program for post-1996 immigrants, and zero otherwise; "neither" is equal to one if a state provides new immigrants neither TANF nor Medicaid, and zero otherwise. The effect of the policy is allowed to be different for both the pre-1996 and post-1995 immigrants, which allows us to test whether any observed differences are because of differences in policy as opposed to differences in unmeasured state effects. As in the previous analysis, recency of immigration is held constant thus, we are comparing the health insurance status of recently arrived immigrants after PRWORA with the health insurance status of recently arrived immigrants before PRWORA. The analysis also has all the controls of the previous analyses.

Estimates in Table 3 are similar to previous estimates and are not greatly affected by the choice of comparison group. Statistical tests reject the hypothesis that the two groups of newly arrived, foreign-born women defined on the basis of substitute TANF and Medicaid policies in their state of residence were differentially affected by PRWORA even though they faced different policy environment. This finding suggests that the fear or confusion caused by the policy may have had a "chilling" effect. Statistical tests also reject the hypothesis that the pre- and post-1996 foreign-born were differentially affected by the policy. Note that although the DD estimates for post- 1996 foreign-born single women may have a greater downward bias as compared with the DDestimates for the pre-1996 foreign-born single women, there is no reason to believe that the degree of bias in the DD estimates for the two groups of post1996 immigrants would be significantly different. ${ }^{17}$

\section{Multivariate Analysis-Children}

In the children's analysis, we focus on three groups: foreign-born children of foreign-born women, U.S.-born children of foreign-born women, and children of U.S.-born women. Table 4 presents the first-difference (sample restricted to target groups only) and DD results of the effect of PRWORA on the target groups. Estimates reported in each cell of rows 1 and 4 of the two tables are from a separate regression; estimates in rows 2 and 3 of each column are from a single regression involving two dummy variables for the target groups: 


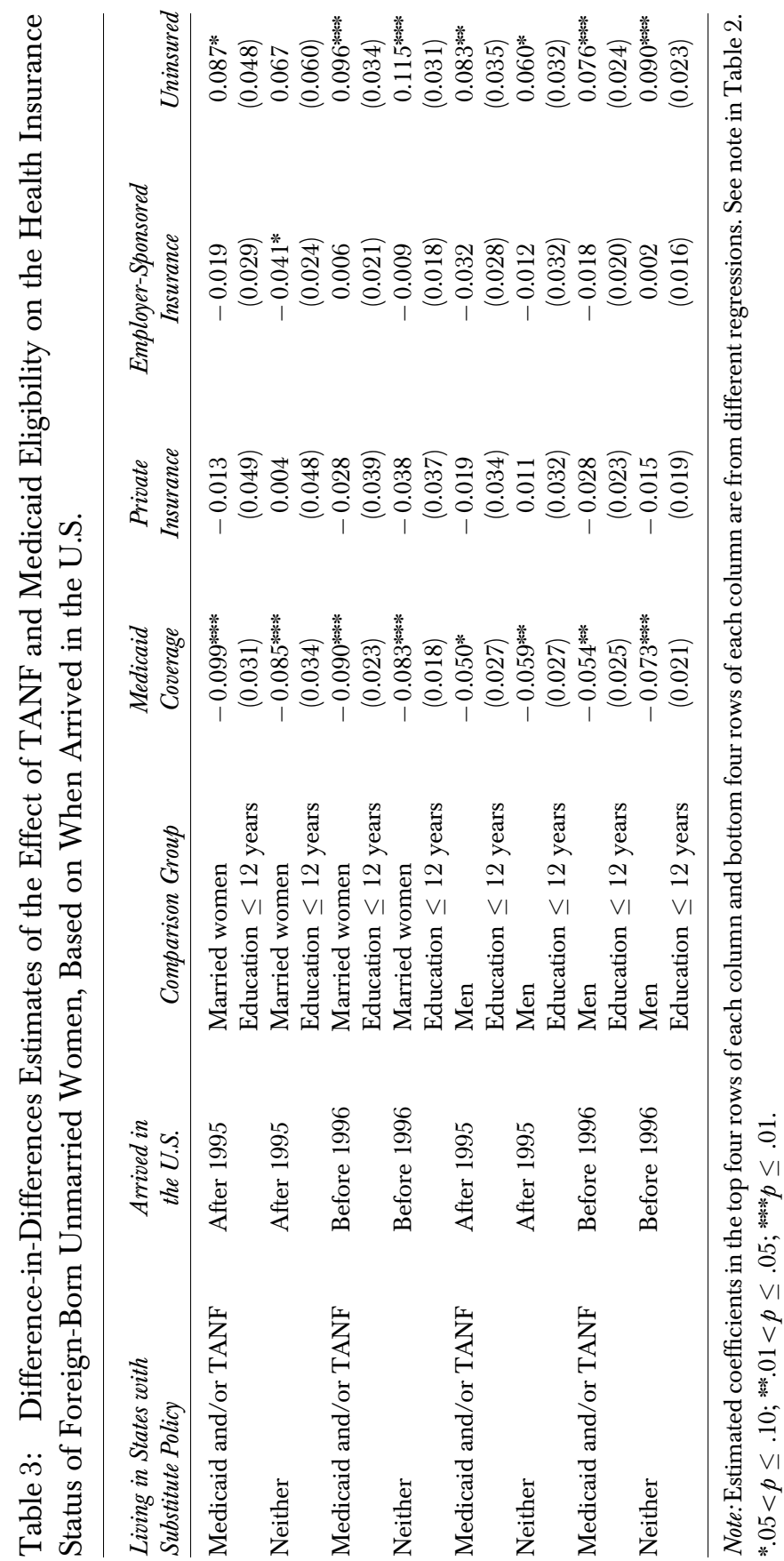




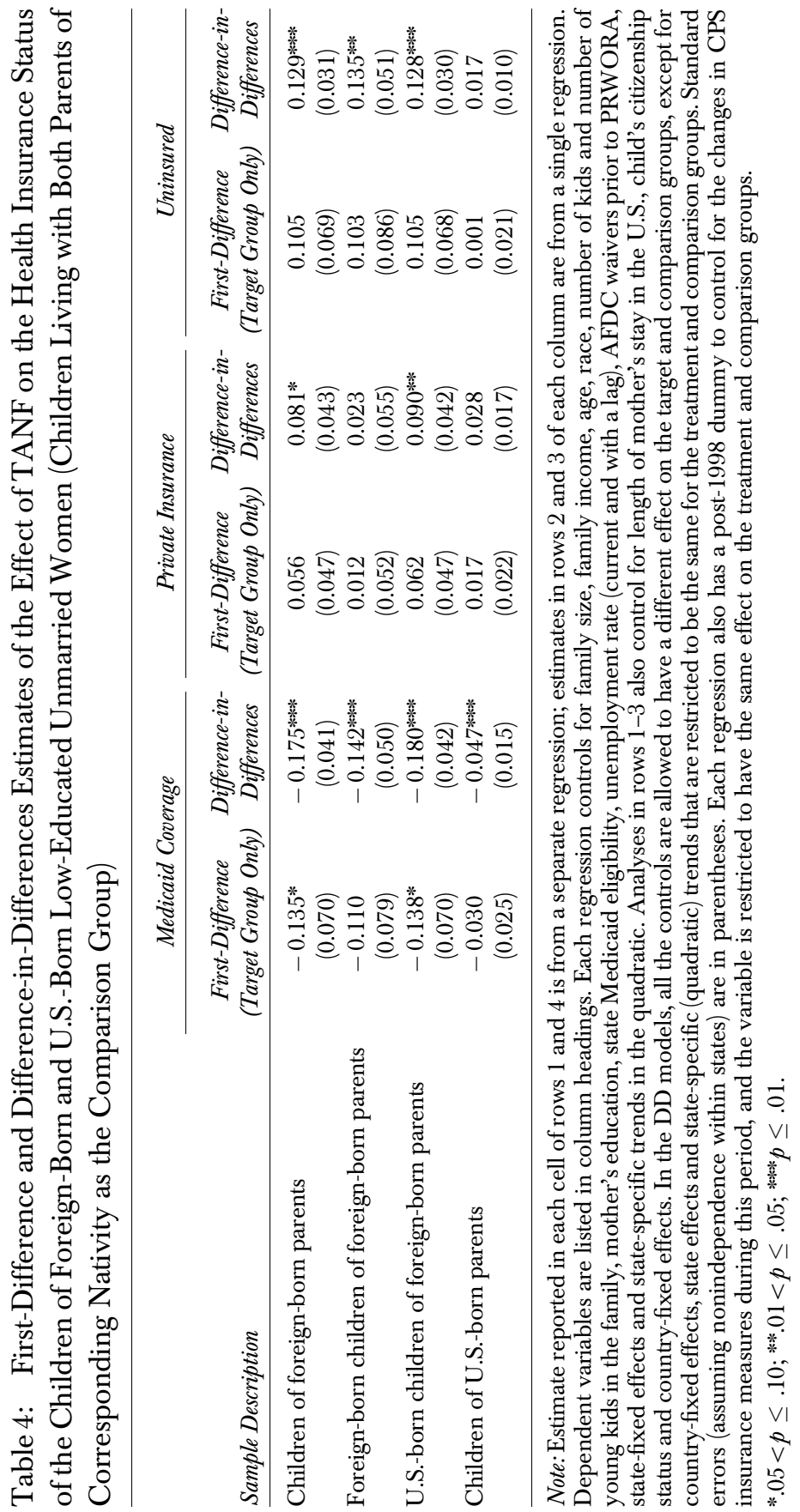


foreign-born children of foreign-born, single mothers and U.S.-born children of foreign-born, single mothers. Each regression controls for family size, mother's education, family income, age, race, number of kids and number of young kids in the family, state Medicaid eligibility, unemployment rate (current and with a lag), whether a state had AFDC waivers prior to PRWORA, a post-1998 dummy, state-fixed effects and state-specific trends in the quadratic. Analyses in rows 1-3 also control for length of mother's stay in the U.S., child's citizenship status, and country-fixed effects.

The first difference results suggest that that PRWORA lowered the Medicaid coverage of children of foreign-born, single mothers by a statistically significant 13.5 percentage points, increased their private insurance by a statistically insignificant 5.6 percentage points, and increased the proportion uninsured by a statistically insignificant 10.5 percentage points. In contrast, PRWORA had a much modest effect on the children of U.S.-born women.

The DD results suggest that PRWORA lowered Medicaid coverage of the children of foreign-born single women by 17.5 percentage points, increased their private insurance by 8.1 percentage points, and increased the proportion without health insurance by 12.9 percentage points. Note that the federal law does not distinguish between the U.S.-born children of foreign-born parents and the children of the U.S.-born. However, our analysis shows that PRWORA lowered the Medicaid coverage of the U.S.-born children of foreign-born parents by 18 percentage points, increased their private coverage by nine percentage points and increased those without health insurance by 12.8 percentage points. In contrast, PRWORA reduced the Medicaid coverage of the children of U.S.-born parents by 4.7 percentage points and had modest and statistically insignificant effects on their private insurance and proportion uninsured. This is evidence in support of the "chilling" hypothesis. Further, statistical tests reject the hypothesis that PRWORA differentially affected the proportion uninsured among U.S.-born children of foreign-born parents as compared with foreign-born children of foreign-born parents. This also supports the "chilling" hypothesis, but it is also possible that the two groups of immigrants' children may have different proportions in the target and comparison groups likely to be affected by PRWORA. Therefore, the (downward) bias of the DD estimates may differ and obscure true underlying differences in effects.

\section{CONCLUSION}

This paper investigated the effect of PRWORA on the health insurance coverage of low-educated, foreign- and U.S.-born, unmarried women and their 
children. We find that federal welfare reform is associated with a 9.9 (21 percent) to 10.7 (23 percent) percentage point increase in the proportion of uninsured low-educated, foreign-born, single women. We also find that welfare reform had no statistically significant effect on the insurance coverage of U.S.-born single women, which is in line with some earlier research on this issue (Kaestner and Kaushal 2003). The larger effect of PRWORA on immigrants than natives is consistent with the "chilling" hypothesis since the immigrant provisions of PRWORA were binding only on a small proportion of foreign-born noncitizens who arrived after 1996 and lived in states that have not created a substitute program for the newly arrived immigrants. An alternative hypothesis is that the jobs that low-educated, foreign-born women obtained in response to PRWORA were much less likely to provide health insurance; there is some evidence that PRWORA was associated with a modest increase in employer-sponsored insurance for U.S.-born women.

The study also suggests that although policies under PRWORA were more severe toward new immigrants, the health insurance status of new immigrants was not differentially affected by the policy change as compared with the insurance status of immigrants who arrived earlier. This is also consistent with the "chilling" hypothesis. Finally, we find that among the post-1996 immigrants, single women living in states with a substitute program for either TANF or Medicaid (or both) seem to have been as adversely affected by the policy change as women living in states with neither program. This is perhaps the most direct evidence in support of the "chilling" hypothesis.

In the children's analysis, we find that welfare reform is associated with a 12.9 (68 percent) percentage point increase in the proportion of uninsured among the children of foreign-born mothers. PRWORA also adversely affected the health insurance coverage of U.S.-born children living with foreignborn mothers; and had no statistically significant effect on the health insurance of the children of U.S.-born single mothers. Again, this is an indication that PRWORA may have engendered fear among immigrants and dampened their enrollment in safety net programs, as PRWORA did not differentiate between U.S.-born children of foreign-born parents and U.S.-born children of U.S.-born parents.

\section{ACKNOWLEDGMENTS}

The authors thank several anonymous referees for extremely helpful comments and suggestions. 


\section{NOTES}

1. Initially, new immigrants were ineligible for Medicaid in New York. A court decision in June 2001, however, rendered that unconstitutional.

2. Increased naturalizations during the nineties fail to explain the trend (Fix and Haskins 2002).

3. PRWORA also changed immigrant eligibility for SSI, and these changes may have also affected immigrants' Medicaid use. However, the target group of welfare reform, primarily consisting of low-educated, nonelderly unmarried women, is different from the population affected by SSI, which largely comprises the elderly. For instance, during 1993-2000, 0.8 percent of foreign-born, low-educated men and 1.5 percent of the foreign-born, low-educated women aged 18-44 received SSI. In contrast, 10 percent of the foreign-born low-educated men and 15 percent of the foreign-born, low-educated women above 59 years of age received SSI.

4. To improve the efficiency of the DD estimates, we tested whether the state-fixed effects and state-specific trends were equal for the target and comparison groups. In the majority of cases, we could not reject the restriction, which is evidence consistent with the identifying assumption that unmeasured state-specific effects are also equal for the target and comparison groups. Similarly, for the analysis of foreign-born persons, we constrained the effects of country dummy variables to be the same for the target and comparison groups after tests of this restriction failed to reject the hypothesis of equality.

5. An alternate hypothesis is that the chilling effect of PRWORA would be greater among U.S.-born children of foreign-born parents than among foreign-born children of foreign-born parents because of the fear among the parents of U.S.-born children about jeopardizing their child's citizenship.

6. Among the U.S.-born unmarried women, 23 percent received welfare and 34 percent were covered by Medicaid.

7. The Medicaid income eligibility thresholds for adults are the same as the AFDC eligibility procedures; the Medicaid income eligibility expansions so prominent during this period pertain to children and pregnant women.

8. Welfare reform may have affected marital status, changing the composition of our target and comparison groups. Existing evidence, however, does not suggest that to be the case (Grogger et al. 2002).

9. We also carry out a placebo test on highly educated women (education $\geq 16$ years) who are generally at low risk of participating in welfare, and find that PRWORA had negligible effect on the health insurance of unmarried, foreign-born, highly educated women with married, highly educated, foreign-born women as the comparison.

10. Medicaid eligibility for children does not depend on mother's marital status to the same extent that it does for adults. The Medicaid expansions were more effective at separating Medicaid eligibility from AFDC eligibility for children (and pregnant women). Therefore, our comparison group approach is more suitable for the public insurance outcome in the analysis of child insurance than in the analysis of adults.

11. Note that the comparison group approach is used to control for unmeasured determinants of health insurance and that many, if not most, of the important 
determinants of Medicaid that vary by state-year such as Medicaid income eligibility level and strength of the economy (unemployment rate) are held constant. The models also include state effects, state-specific trends and personal characteristics, and so the omitted variable problem may not be severe.

12. A quarter of the sample in the analysis on the foreign-born consists of citizens. We also repeat the analysis by limiting the sample to foreign-born noncitizens. The results do not differ, which is indicative of some evidence of the chilling effect.

13. In the analysis, persons covered by CHAMPUS or Indian Health Service are excluded from both public and private insurance categories.

14. We thank Aaron Yellowitz for providing us with the Medicaid income eligibility data.

15. We decided to introduce time-effects as a quadratic state-specific trend because there is a high degree of collinearity between the policy variable and year effects. A regression of policy on state and year fixed effects yields an $R^{2}$ of 0.91 . To test the validity of our model, we first estimated a model with year effects and then a model with state-specific quadratic trends. The second model used 102 parameters to measure state-specific time effects while the first used eight parameters (for 8 years). An $F$-test rejected the first model.

16. Our estimates would be biased if the post-1996 immigrants chose to stay in states that provide them benefits. To see whether our estimates carry that bias we redo the entire analysis after excluding from the sample individuals who arrived in the U.S. after 1996. The results are similar to what we obtain with the full sample including post-1996 immigrants. This is expected as research shows that new immigrants do not choose their state of residence on the basis of benefit availability (Kaushal 2005). This is also an indicator that the results presented here are not driven by the presence of post-PRWORA immigrants in the sample.

17. We repeated the above analysis on native-born women to test if there are systematically different trends across states that have substitute programs for post-1996 immigrants (replacement states) and those that have not chosen to provide substitute programs for post-1996 immigrants (nonreplacement states). We found that Medicaid use of low-educated, unmarried women living in nonreplacement states, declined by a statistically significant 4.1 percentage points; of those living in replacement states Medicaid use fell by a statistically insignificant 1.6 percentage points. The proportion without insurance in nonreplacement states rose by 1.9 percentage points and remained unchanged in replacement states. The differences in estimated effects for women living in replacement and nonreplacement states were statistically significant. This may suggest that the non-replacement states were in general more aggressive in carrying out welfare reform as compared with the replacement states.

\section{REFERENCES}

Borjas, G. 2003. "Welfare Reform, Labor Supply and Health Insurance in the Immigrant Population." Journal of Health Economics 22: 933-58. 
Camarota, S. A., and J. R. Edwards Jr. 2000. Without Coverage: Immigration's Impact on the Size and Coverage of the Population Lacking Health Insurance. Washington, DC: Center for Immigration Studies.

Families USA Foundation. 1999. Losing Health Insurance: The Unintended Consequences of Welfare Reform. Washington, DC: Families USA Foundation.

Fix, M., and J. Passel. 1999. Trends in Noncitizens' and Citizens' Use of Public Benefits Following Welfare Reform: 1994-97. Washington, DC: Urban Institute.

Fix, M., and R. Haskins. 2002. "Welfare Benefits for Non-citizens. Welfare Reform and Beyond.” Policy Brief No. 15. Washington, DC: The Brookings Institution.

Grogger, J., L. A. Karoly, and J. A. Klerman. 2002. "Consequences of Welfare Reform: A Research Synthesis.” RAND Labor and Population Program. DRU-2676DHHS.

Nelson, C. T., and R. J. Mills. 2001. "The March CPS Health Insurance Verification Question and Its Effect on Estimates of the Uninsured." U.S. Census Bureau. Available at http://www.census.gov/hhes/hlthins/verif.html

Kaestner, R., and N. Kaushal. 2003. "Welfare Reform and Health Insurance Coverage of Low-Income Families.” Journal of Health Economics 22: 959-81.

Kaushal, N. 2005. "New Immigrants' Location Choices: Magnets without Welfare." Journal of Labor Economics 23 (1): 59-80.

Kronebusch, K. 2001. "Medicaid for Children: Federal Mandates, Welfare Reform, and Policy Backsliding." Health Affairs 20: 97-111.

Ku, L., and B. Garrett. 2000. "How Welfare Reform and Economic Factors Affected Medicaid Participation." 1984-96. Discussion Paper, Assessing the New Federalism. Washington, DC: Urban Institute.

Schlosberg, C., and D. Wiley. 1998. "The Impact of INS Public Charge Determinants on Immigrant Access to Health Care.” Available at http://www.healthlaw.org/ pubs/19980522publiccharge.html

Zimmerman, W., and K. Tumlin. 1999. "Patchwork Policies: State Assistance for Immigrants under Welfare Reform.” Occasional Paper Number 24. Washington, DC: Urban Institute. 
